\title{
Transmission of Pantoea ananatis and P. agglomerans, Causal Agents of Center Rot of Onion (Allium cepa), by Onion Thrips (Thrips tabaci) Through Feces
}

\author{
B. Dutta, A. K. Barman, R. Srinivasan, U. Avci, D. E. Ullman, D. B. Langston, and R. D. Gitaitis
}

First, sixth, and seventh authors: Department of Plant Pathology, Coastal Plain Experiment Station, University of Georgia, Tifton, GA 31793; second and third authors: Department of Entomology, Coastal Plain Experiment Station, University of Georgia, Tifton, GA 31793; fourth author: Complex Carbohydrate Research Center, University of Georgia, Athens, GA 30602; and fifth author: Department of Entomology, University of California, Davis, CA 95616.

Accepted for publication 10 February 2014.

\begin{abstract}
Dutta, B., Barman, A. K., Srinivasan, R., Avci, U., Ullman, D. E., Langston, D. B., and Gitaitis, R. D. 2014. Transmission of Pantoea ananatis and P. agglomerans, causal agents of center rot of onion (Allium cepa), by onion thrips (Thrips tabaci) through feces. Phytopathology 104:812-819.

Frankliniella fusca, the tobacco thrips, has been shown to acquire and transmit Pantoea ananatis, one of the causal agents of the center rot of onion. Although Thrips tabaci, the onion thrips, is a common pest of onions, its role as a vector of $P$. ananatis has been unknown. The bacterium, $P$. agglomerans, is also associated with the center rot of onion, but its transmission by thrips has not been previously investigated. In this study, we investigated the relationship of $T$. tabaci with $P$. ananatis and $P$.

agglomerans. Surface-sterilized T. tabaci were provided with various acquisition access periods (AAP) on onion leaves inoculated with either $P$. ananatis or $P$. agglomerans. A positive exponential relationship was observed between thrips AAP duration and $P$. ananatis $\left(R^{2}=0.967 ; P=\right.$ $0.023)$ or $P$. agglomerans acquisition $\left(R^{2}=0.958 ; P=0.017\right)$. Transmission experiments conducted with T. tabaci adults indicated that $70 \%$ of the seedlings developed center rot symptoms 15 days after inoculation. Immunofluorescence microscopy with antibodies specific to $P$. ananatis revealed that the bacterium was localized only in the gut of $T$. tabaci adults. Mechanical inoculation of onion seedlings with fecal rinsates alone produced center rot but not with salivary secretions. Together these results suggested that $T$. tabaci could efficiently transmit $P$. ananatis and P. agglomerans.
\end{abstract}

Since its first report on Vidalia sweet onion in Georgia in 1997 (10), center rot of onion (Allium cepa L.), caused by a gramnegative, facultative-anaerobic bacterium, Pantoea ananatis (Serrano) Mergaert, has been a chronic threat to onion producers in Georgia and other onion producing states. The symptoms of center rot include white streaks with water-soaked margins that run along the length of the leaf. As the disease progresses, the streaks turn necrotic and blighted. In severe cases, infected plants may wilt and exhibit bleaching of the foliage. The bacterium may also infect the bulb and predispose it to rotting caused by secondary microbes in storage. The internal tissues of infected bulbs exhibit discoloration, and further colonization by secondary microbes might result in liquefaction of bulb tissues. Under favorable conditions, yield losses to this disease may be as high as $100 \%(9,10,20)$. In addition to onion, $P$. ananatis has been associated with a number of diseases on different hosts such as Cucumis melo var. cantalupensis L., Eucalyptus sp. L., Cucumis melo L., Ananas comosus (L.) Merr., Zea mays L., Sorghum vulgare var. drummondii (Nees ex Steud.) Hitchc, and Lycopersicon esculentum L. (1,3,4,14,21,22,28,33). Besides being a pathogen of onion plants, $P$. ananatis also resides as a common epiphyte on more than 20 weed species in onion farmscapes of Georgia (12). The role of these alternate weed hosts as inoculum sources of the bacterium is unclear. $P$. ananatis could be transmitted via seeds, but transmission by thrips is considered to be the primary mode of spread (12,32). A closely related bacterium, P. agglomerans (syn.

Corresponding author: Bhabesh Dutta, email: bhabesh@uga.edu

http://dx.doi.org/10.1094/PHYTO-07-13-0199-R

(c) 2014 The American Phytopathological Society
Erwinia herbicola), was also identified as a causal agent of center rot of onions in Georgia in 2006 (8). This was the first report of $P$. agglomerans causing center rot of onion in the United States, although this species had been reported causing a disease of onion in South Africa in 1981 (14). The long-term impact of P. agglomerans on the onion industry in Georgia is unknown, but considering that it is closely related to $P$. ananatis and produces similar symptoms, it has the potential to cause economic losses in Georgia.

In onion farmscapes of Georgia, thrips (Thysanoptera: Thripidae) transmit pathogens that cause center rot. The ability of tobacco thrips, Frankliniella fusca (Hinds), to acquire and transmit $P$. ananatis was demonstrated earlier $(10,32)$, although the mechanism of transmission has not been elucidated. Onion thrips, Thrips tabaci (Lindeman), populations have been consistently increasing in recent years in Georgia $(7,24)$ and this species is also the most prevalent thrips on onion in many parts of the world (29). The ability of $T$. tabaci to acquire and transmit $P$. ananatis or other center rot causing pathogens has not been previously investigated. Thrips are known to transmit tospoviruses in a very active manner that involves persistence and propagation in the vector $(19,29)$. Interactions between thrips and plant-pathogenic bacteria are poorly understood. It is not clear if bacterial plant pathogens are transmitted by thrips through salivation while feeding or by other means, such as contaminated feces and injuries induced by feeding. Other insects such as beetles (Coleoptera: Chrysomelidae), flies (Diptera: Anthomyiidae), leafhoppers (Cicadellidae: Cicadellinae), and fleahoppers (Hemiptera: Miridae) are known to transmit bacteria in the family Enterobacteriaceae $(2,5,17)$. It has been widely presumed that insects transmit members of the family Enterobacteriaceae through contaminated feces and feedinginduced injuries (17). On the contrary, recent studies indicated 
specificity in the transmission of $P$. ananatis and $P$. agglomerans (Enterobacteriaceae members) by leafhoppers $(2,16)$.

The objectives of this study were to determine whether $T$. tabaci could transmit $P$. ananatis and/or $P$. agglomerans, and characterize their transmission processes. We used immunolocalization to determine distribution of $P$. ananatis in thrips, and elucidated the role of thrips salivary secretions and fecal rinsates in $P$. ananatis transmission.

\section{MATERIALS AND METHODS}

Bacterial strains and inoculum preparation. The strains PNA 97-1 (accession no. DQ777968) and PNG 06-1 (accession no. KF805975) of $P$. ananatis and $P$. agglomerans, respectively, were used in this study $(6,9)$. These strains were isolated from symptomatic onion foliage showing center rot symptoms, and their pathogenicity was confirmed on onion seedlings as described previously $(6,9)$. The strains were routinely grown on trypticase soy broth agar (TSBA) for $48 \mathrm{~h}$ at $28^{\circ} \mathrm{C}$. To prepare the inoculum, $3 \mathrm{ml}$ of nutrient broth was inoculated with single colonies of each bacterial strain from a 48-h-old agar culture and incubated overnight at $28^{\circ} \mathrm{C}$ on a rotary shaker (Innova; New Brunswick Scientific, Edison, NJ) at $150 \mathrm{rpm}$. After incubation, $3 \mathrm{ml}$ of bacterial suspension was centrifuged at $6,000 \times g$ (Allegra 25R, Beckman Coulter, Fullerton, CA) for 5 min. The supernatant was discarded and the pellet was resuspended in $1 \mathrm{ml}$ of $0.1 \mathrm{M}$ phosphate-buffered saline (PBS). The bacterial concentration was adjusted to an optical density of 0.3 at $600 \mathrm{~nm}\left(\approx 1 \times 10^{8} \mathrm{CFU} / \mathrm{ml}\right)$ using a spectrophotometer (Spectronic 20; Bausch and Lomb, Rochester, NY). Tenfold serial dilutions were made in $1 \mathrm{ml}$ of $0.1 \mathrm{M}$ PBS to obtain a desired bacterial concentration of $1 \times 10^{6}$ $\mathrm{CFU} / \mathrm{ml}$. After adjusting the inoculum concentration, confirmation of bacterial populations was conducted by dilution plating of $0.1 \mathrm{ml}$ aliquots on nutrient agar.

Collection and maintenance of $\boldsymbol{T}$. tabaci in the laboratory. Onion thrips were collected from an onion field in Reidsville, GA in 2012 and were reared at the University of Georgia-Coastal Plain Experiment Station (UGA-CPES), Department of Entomology. Thrips populations were maintained continuously on $P$. ananatis- and $P$. agglomerans-free onion plants in an isolated rearing room for at least 10 generations (25). Plating of crushed thrips from the same onion plants produced no bacterial growth suggesting absence of Pantoea infection in thrips. To confirm if the onion plants were negative for the two bacterial species, $5 \mathrm{~cm}$ leaf segments were sampled $(n=5)$ and without surface-sterilization, the samples were rinsed in $2 \mathrm{ml}$ of $0.1 \mathrm{M}$ PBS for $2 \mathrm{~min}$ and an aliquot of $0.1 \mathrm{ml}$ was spread-plated on to both PA-20 (13) and TSBA plates and incubated for $48 \mathrm{~h}$ at $28^{\circ} \mathrm{C}$ as described below. After incubation at $28^{\circ} \mathrm{C}$ for $48 \mathrm{~h}$, plates were assessed for $P$. ananatis and $P$. agglomerans bacterial colonies. The conditions for rearing were $27^{\circ} \mathrm{C}, 50$ to $75 \%$ relative humidity $(\mathrm{RH})$, and a 12-h light/12-h dark photoperiod. The majority ( $>95 \%$ ) of individuals in the colonies were females. Hence, only adult female thrips were used in all experiments.

Surface sterilization of onion leaf segments and adult onion thrips. Onion leaves were collected from thrips-free plants maintained in the greenhouse. Onion leaves were cut into $5 \mathrm{~cm}$ leaf segments using a pair of sterile scissors, surface sterilized using $10 \% \mathrm{NaOCl}$ for $30 \mathrm{~s}$, and transferred to $70 \%$ ethanol for an additional $30 \mathrm{~s}$. After rinsing twice in $2 \mathrm{ml}$ of $0.1 \mathrm{M}$ PBS, leaf segments were placed in individual petri plates with partially opened lids and air dried in a laminar airflow chamber for 15 to $20 \mathrm{~min}$. After drying, individual leaf segments were placed in separate $1.5-\mathrm{ml}$ microcentrifuge tubes. In order to assess the efficiency of surface sterilization, $0.1 \mathrm{ml}$ rinsates of five individual leaf segments from the last rinsing step were spread-plated in replicates $(n=3)$ on to both PA-20 and TSBA plates and incubated for $48 \mathrm{~h}$ at $28^{\circ} \mathrm{C}$.
Adult thrips, collected randomly from the laboratory-maintained colony, were surface-sterilized using the same procedure as described above. Rinsates from five replicates (from last rinsing step with PBS) of 10 thrips were assessed separately by spread plating $0.1 \mathrm{ml}$ aliquots on PA-20 and TSBA plates, respectively. The agar plates were incubated for $48 \mathrm{~h}$ at $28^{\circ} \mathrm{C}$. Furthermore, to determine if laboratory-reared thrips harbored $P$. ananatis and $P$. agglomerans in their gut, three replicates of 10 surfacesterilized thrips were macerated individually in $1.5 \mathrm{ml}$ microcentrifuge tubes with $1 \mathrm{ml}$ of $0.1 \mathrm{M}$ PBS. Aliquots of $0.1 \mathrm{ml}$ from thrips macerates were spread-plated onto both PA-20 and TSBA agar plates. Upon incubation at $28^{\circ} \mathrm{C}$ for $48 \mathrm{~h}$, plates were assessed for P. ananatis and P. agglomerans bacterial colonies.

Confirming $\boldsymbol{P}$. ananatis and $\boldsymbol{P}$. agglomerans presence. Bacterial colonies were characterized by the presence of a yellow pigment and morphology on TSBA, Gram reaction, utilization of glucose in oxidative and fermentative reaction, indole reaction, and nitrate reductase reaction. Furthermore, real-time polymerase chain reaction (PCR) specific for $P$. ananatis was also conducted on three random colonies per agar plate. A single bacterial colony was suspended in $25 \mu \mathrm{l}$ of sterile deionized water and heated (Modular Dry Block Heaters, Cole Parmer, IL) for $3 \mathrm{~min}$ at $95^{\circ} \mathrm{C}$. Five microliters of boiled cells was amplified in $25 \mu \mathrm{l}$ of PCR master-mix containing $10 \mathrm{mM}$ Tris- $\mathrm{HCl}(\mathrm{pH} 9.0), 50 \mathrm{mM} \mathrm{KCl}$, $0.1 \%$ Triton X-100, $1.5 \mathrm{mM} \mathrm{MgCl} 2$, and $0.2 \mathrm{mM}$ of each nucleotide (dATP, dCTP, dGTP, and dTTP), $25 \mu \mathrm{M}$ each of primer PanITS1 (5'-GTCTGATAGAAAGATAAAGAC-3') and EC5 (5'CGGTGGATGCCCTGGCA-3') and $10 \mu \mathrm{M}$ of TaqMan probe 6-FAM TAGCGGTTAGGACTCCGCCCTTTCA-BHQ. DNA amplification was carried out in a Cepheid Smart Cycler (Sunnyvale, CA) using the following thermal profile: denaturation at $95^{\circ} \mathrm{C}$ for $180 \mathrm{~s}, 35$ cycles each of denaturation at $95^{\circ} \mathrm{C}$ for $15 \mathrm{~s}$, and annealing at $60^{\circ} \mathrm{C}$ for $40 \mathrm{~s}$. Samples with cycle threshold $(\mathrm{Ct})$ values less than 35 were considered positive for $P$. ananatis. For $P$. agglomerans, total microbial DNA was extracted from three colonies per isolation from five agar plates $(n=15)$ using an UltraClean Microbial DNA Kit (MO BIO, Carlsbad, CA) according to manufacturer's instructions. Two microliters of bacterial DNA was amplified in $25 \mu \mathrm{l}$ of PCR master mix using the $16 \mathrm{~S}$ rRNA primer pair (fD1 AGAGTTTGATCCTGGCTCAG and rD1 AAGGAGGTGATCCAGCC) as described by Weisburg et al. (31). The PCR amplicon was purified using an affinity column (Wizard PCR Preps DNA Purification System, Promega) and sequenced at the Eurofins MWG Operon DNA sequencing facility (Huntsville, AL). The sequences were compared with the sequence of the same $P$. agglomerans strain (PNG 06-1).

Acquisition of $P$. ananatis or $P$. agglomerans by adult $T$. tabaci study. Surface-sterilized onion leaf segments (length $=5 \mathrm{~cm}$ ) were air-dried and placed in a $1.5-\mathrm{ml}$ microcentrifuge tube containing $1 \mathrm{ml}$ of $1 \times 10^{6} \mathrm{CFU} / \mathrm{ml}$ of either $P$. ananatis or $P$. agglomerans. Leaf segments were incubated for $5 \mathrm{~min}$. Two to three onion leaf segments were dipped in bacterial suspension containing $1 \times 10^{6} \mathrm{CFU}$ of $P$. ananatis or $P$. agglomerans and placed inside Munger cells $\left(11.5 \times 9 \mathrm{~cm}^{2}\right)(18)$ lined with a moistened filter paper (Whatman No. 2). Five cells were used for each bacterial species. Onion leaf segments incubated in PBS and airdried as described above were also kept inside the Munger cells as described above. Fifty to sixty negative adult T. tabaci (females) were released per Munger cell. To assess the efficiency of thrips acquiring bacteria, a time course study was conducted. At each acquisition access period (AAP) $(1,6,12,24$, and $48 \mathrm{~h}$ ), four individual adult thrips were randomly sampled from each Munger cell and placed into separate 1.5- $\mathrm{ml}$ microcentrifuge tubes. Collected thrips were assayed separately for the presence of bacteria using spread-plating on a semiselective medium as described previously. Thrips fed on PBS-inoculated leaves served as negative controls. Percentages of thrips positive for $P$. ananatis and $P$. agglomerans at different AAPs were recorded. Regression analy- 
sis was used to determine the relationship between AAP and percentage of thrips acquiring $P$. ananatis or $P$. agglomerans using SigmaPlot (version 10.0; Systat, San Jose, CA). Regression analysis was based on means from six experiments after a preliminary analysis of variance (ANOVA) (PROC GLM in SAS, version 9.1; SAS Institute, Cary, NC) showed no significant effect of the experiment factor at $P=0.05$.

Transmission of center rot of onion by $P$. ananatis or $P$. agglomerans-positive T. tabaci. Onion seedlings ('Century') were planted in pots (Hummert International, Earth City, MO) $(10 \mathrm{~cm}$ $\times 8 \mathrm{~cm}$, diameter $\times$ height) in a commercial potting mix (Sunshine LP5 Plug Mix; sun Gro Horticulture Industries, Bellevue, WA) in the greenhouse and maintained at 25 to $28^{\circ} \mathrm{C}$ and 80 to $90 \% \mathrm{RH}$ with a 12-h light/12-h dark photoperiod. Sixty to seventy adult thrips were exposed to epiphytic populations of $P$. ananatis or $P$. agglomerans (onion leaves were dipped in bacterial suspension of $1 \times 10^{6} \mathrm{CFU} / \mathrm{ml}$ ) on onion leaves for $48 \mathrm{~h}$. After an AAP of $48 \mathrm{~h}$, thrips were removed and surface-sterilized as described above. Following surface sterilization, thrips ( $n=3$ thrips/plant) were exposed to 2-week-old healthy onion seedlings covered by a Mylar film cage with a copper mesh $(\approx 200 \mu \mathrm{m})$ (Grafix Plastics, Cleveland, $\mathrm{OH}$ ) in the greenhouse as described above. The treatments for this experiment included (i) thrips that were exposed to $P$. ananatis-inoculated noninfected onion seedlings; (ii) thrips that were exposed to $P$. agglomerans-inoculated noninfected onion seedlings; (iii) noninfected onion seedlings exposed to thrips that fed on PBS-inoculated leaves; and (iv) noninfected onion seedlings that were mechanically inoculated with $P$. ananatis or $P$. agglomerans. Mechanical inoculation was done by clipping seedlings with a pair of sterile scissors at approximately $5 \mathrm{~cm}$ below the apex. Using a micropipette, four $10 \mu \mathrm{l}$ drops (diagonally opposite) of bacterial suspensions containing $1 \times 10^{8} \mathrm{CFU} / \mathrm{ml}\left(\approx 1 \times 10^{6} \mathrm{CFU} / \mathrm{ml}\right)$ of either $P$. ananatis or $P$. agglomerans were placed at the cut ends of the seedlings. Seedlings mechanically inoculated with PBS as described above were used as negative controls. Ten replications per treatment were used in two independent trials. Seedlings were checked visually for symptom development at 3-day-intervals for 15 days. Mean percentage of center rot incidence in each treatment was recorded 15 days after inoculation and area under disease progress curve (AUDPC) was determined. ANOVA was conducted to determine the significance of treatment effects on disease incidence, and Tukey's test was used to compare treatment means.

Confirmation of center rot of onion symptomatic seedlings. To confirm that the symptoms observed on seedlings were caused by $P$. ananatis and $P$. agglomerans, bacterial isolations were performed on four seedlings per treatment. Small pieces $\left(2 \mathrm{~mm}^{2}\right)$ of tissue bordering the symptomatic and asymptomatic areas were macerated using a sterile scalpel with a \#3 blade (DR Instruments, Palos Hills, IL) in $20 \mu \mathrm{l}$ of $0.1 \mathrm{M}$ PBS. Tissue macerates were streaked onto both PA-20 and TSBA agar plates and incubated for $48 \mathrm{~h}$ at $28^{\circ} \mathrm{C}$. After incubation, bacterial colonies were characterized based on morphology, gram-reaction, oxidative and fermentative utilization of glucose, indole reaction, and nitrate reductase test. Furthermore, $P$. ananatis colonies were confirmed by species-specific TaqMan real-time PCR assay, whereas $P$. agglomerans colonies were identified by amplification and partial sequencing 16S rRNA gene followed by comparison with the sequence of PNG 06-1.

Immunolocalization of $\boldsymbol{P}$. ananatis in adult $\boldsymbol{T}$. tabaci. Adult T. tabaci $(n=15)$ were allowed to feed on P. ananatis-inoculated onion leaves for $48 \mathrm{~h}$ and sampled for immunofluorescence microscopy. Thrips fed on PBS-inoculated onion leaves served as negative controls. Samples were fixed for $24 \mathrm{~h}$ in $1.6 \%(\mathrm{wt} / \mathrm{vol})$ paraformaldehyde and $0.2 \%$ (wt/vol) glutaraldehyde in $25 \mathrm{mM}$ sodium phosphate buffer $\left(\mathrm{pH} \mathrm{7.1)}\right.$ at $4^{\circ} \mathrm{C}$. The fixed samples were washed with $25 \mathrm{mM}$ phosphate buffer (three times for $5 \mathrm{~min}$ each), water (two times for 5 min each), and dehydrated using the following ascending ethanol series: $35 \%, 50 \%, 75 \%, 85 \%, 95 \%$, $100 \%, 100 \%$, and $100 \%$ [vol/vol] for $5 \mathrm{~min}$ at each step. The dehydrated tissues were gradually infiltrated with LR White embedding resin (Ted Pella Inc., Redding, CA) using 33\% (vol/vol) and $66 \%$ (vol/vol) resin in $100 \%$ ethanol for $24 \mathrm{~h}$ each, followed by three repeated incubation steps with $100 \%$ resin for $24 \mathrm{~h}$ each. The resin-infiltrated samples were transferred to gelatin capsules containing fresh $100 \%$ LR White resin and polymerized (VWR, OR) at $45^{\circ} \mathrm{C}$ for $24 \mathrm{~h}$ and then $55^{\circ} \mathrm{C}$ for an additional $24 \mathrm{~h}$. Longitudinal sections $(250 \mathrm{~nm})$ of thrips were made using a Leica EM UC6 ultra-microtome (Leica Microsystems, Austria) and mounted on glass slides. For immunolabeling of $P$. ananatis, sections were blocked with $3 \%$ (wt/vol) non-fat dry milk in $0.01 \mathrm{M}$ potassium phosphate, $\mathrm{pH} 7.1$, containing $0.5 \mathrm{M} \mathrm{NaCl}$ (KPBS) for $1 \mathrm{~h}$ and washed with $10 \mathrm{mM}$ KPBS three times for $5 \mathrm{~min}$ each. The primary antibody, polyclonal rabbit anti-PNA (30), was diluted $1: 10$ in $3 \%$ bovine serum albumin (BSA) in $10 \mathrm{mM}$ KPBS and $10 \mu \mathrm{l}$ was applied to the thrips sections and incubated for 60 to $90 \mathrm{~min}$. Sections were then washed with BSAKPBS three times for 2 min each, and $10 \mu \mathrm{l}$ of a 1:100 dilution of anti-rabbit immunoglobulin $\mathrm{G}$ (IgG) conjugated to Alexa-fluor 488 (Life Technologies Corp., Grand Island, NY) in BSA-KPBS was applied and incubated for $60 \mathrm{~min}$. Finally, sections were washed with BSA-KPBS and then with distilled water for $5 \mathrm{~min}$ each. Before placing the coverslip on the sections, $10 \mu \mathrm{l}$ of Citifluor antifade mounting medium AF1 (Electron Microscopy Sciences, Hatfield, PA) was applied. Some thrips sections were stained with $0.05 \%$ toluidine blue to visualize the arrangement of thrips tissues and internal organs. The immunolabeled sections were observed with an Eclipse 80i microscope (Nikon Instruments Inc., Melville, NY) and bacterial localization in thrips was documented at 48-h AAP.

Transmission of $P$. ananatis and $P$. agglomerans to onion seedlings by contaminated $\boldsymbol{T}$. tabaci feces. Three subsets $(n=15$ per subset) of laboratory maintained thrips (negative for $P$. ananatis or $P$. agglomerans) were allowed to feed on epiphytic populations of $P$. ananatis (leaves dipped in bacterial suspension of $1 \times 10^{6}$ $\mathrm{CFU} / \mathrm{ml}$ ) on onion leaves for $72 \mathrm{~h}$, after which, thrips were surface-sterilized and transferred to sterile $1.5-\mathrm{ml}$ microcentrifuge tubes. The surface sterilization rinsates, from the last rinse, were spread-plated and tested for the presence of $P$. ananatis as previously described. The opening of each tube was sealed with stretched Parafilm (American Can Company, Greenwich, CT) to facilitate thrips probing and feeding. A drop $(50 \mu \mathrm{l})$ of sucrose solution ( $7 \% \mathrm{wt} / \mathrm{vol})$ was placed on top of the Parafilm. A second layer of Parafilm, stretched likewise, was placed at the top of the first layer. For aeration, two to three holes were made on the Parafilm using a fine entomological pin (Indigo Instruments, Tonawanda, NY). After 3 days, thrips were removed. Thrips feces were collected by thoroughly rinsing the tubes with sterile PBS $(500 \mu \mathrm{l})$. Adult thrips fed on PBS-inoculated onion leaves and processed likewise for feces collection served as negative controls. Later, $0.1 \mathrm{ml}$ of the rinsed buffer from each subset was placed at the cut end of an onion leaf. Onion seedlings were scored for the presence of center rot symptoms at 5 days postinoculation (DPI). Onion leaves inoculated with $1 \times 10^{6} \mathrm{CFU} / \mathrm{ml}$ of $P$. ananatis as described above served as positive controls. Percentage of onion seedlings with center rot symptoms was recorded. In addition, samples of $0.1 \mathrm{ml}$ of feces rinsates from each thrips subset were plated on PA-20 agar plates, and the presence of bacterial colonies was determined after $48 \mathrm{~h}$ of incubation at $28^{\circ} \mathrm{C}$. Ten replicates were used in a single experiment, and the experiment was repeated two times. In addition, to ascertain if $P$. ananatis persisted in thrips saliva, sucrose solution trapped between the two Parafilm layers was collected and processed as described above for $P$. ananatis detection by spread-plating on PA-20 medium. 


\section{RESULTS}

Surface sterilization of onion leaf segments and adult onion thrips. Bacterial colonies were not isolated from the rinsates of the surface-sterilized, noninfected, onion leaf segments on the agar plates (TSBA and PA-20). In addition, bacterial colonies were not recovered from the rinsates of $T$. tabaci after surface sterilization. However, when surface-sterilized T. tabaci were macerated and plated on agar plates, bacterial colonies were recovered. Bioassays indicated that the isolated bacterial species were not $P$. ananatis (biochemical and real-time PCR assays) or P. agglomerans (biochemical assay and sequencing of 16S rRNA gene), but were Serratia sp. (accession no. KF819360), Pseudomonas fluorescens (accession no. KF840372), Xanthomonas sp. (accession no. KF874494), and Dickeya sp. (accession no. KF819361).

Acquisition of $P$. ananatis or $P$. agglomerans by adult T. tabaci. Adult thrips fed on PBS-inoculated onion leaf controls acquired neither $P$. ananatis nor $P$. agglomerans after an AAP of $48 \mathrm{~h}$. From infected onion leaves, mean percentages of $P$. ananatis acquisition after 1- and 6-h AAP were 20.8 and 58.3\%, respectively (Fig. 1A). The mean percentages of $P$. agglomerans acquisition after 1- and 6-h AAP were 12.5 and $37.5 \%$, respectively (Fig. 1B). In contrast, after 24-h AAP, 83.3 and $50 \%$ of the $T$. tabaci were positive for $P$. ananatis and $P$. agglomerans, respectively. A positive exponential relationship was observed between AAP duration and percentages of thrips acquiring $P$. ananatis $\left(R^{2}=0.967 ; P=0.023\right)$. All thrips acquired P. ananatis after 48-h AAP (Fig. 1A). An exponential relationship was also observed between AAPs and percentages of thrips acquiring $P$. agglomerans $\left(R^{2}=0.958 ; P=0.017\right)$, with $92 \%$ of the thrips acquiring the bacterium (Fig. 1B) after 48-h AAP.

Development of center rot of onion following transmission of $\boldsymbol{P}$. ananatis or $\boldsymbol{P}$. agglomerans by $\boldsymbol{T}$. tabaci. Onion seedlings exposed to thrips that fed on PBS-inoculated leaves or seedlings mechanically inoculated with PBS (negative controls) did not develop center rot symptoms (Fig. 2E and F). AUDPC was not significantly different $(P=0.326)$ for seedlings inoculated with either bacterium as well as inoculated by either method (mechanical or by infected thrips). In addition, AUDPC for seedlings was not significantly different for transmission of the two bacterial species by $T$. tabaci $(P=0.421)$. At 3 DPI, 50 and $40 \%$ of the seedlings mechanically inoculated with $P$. ananatis and $P$. agglomerans, respectively, were symptomatic. During the same period, symptoms were not observed from seedlings inoculated with $P$. ananatis- or $P$. agglomerans-exposed thrips. At 6 and 9 DPI, seedlings inoculated with $P$. ananatis developed center rot symptoms in 20 and $50 \%$ of the seedlings, respectively. Similarly, at 6 and 9 DPI, seedlings inoculated with P. agglomerans-exposed thrips, 30 and $60 \%$ of the seedlings developed center rot symptoms, respectively. In contrast, 70 and $90 \%$ of the onion seedlings mechanically inoculated with only $P$. ananatis were symptomatic at 6 and 9 DPI, respectively. Sixty and ninety percent of the onion seedlings mechanically inoculated with only P. agglomerans were symptomatic at 6 and 9 DPI, respectively. By 12 DPI, 100\% of the mechanically inoculated seedlings were symptomatic for both bacterial species (Fig. 2C and D). In contrast, at 12 and 15 DPI, 60 and $70 \%$ of seedlings inoculated with thrips were symptomatic, respectively. For seedlings inoculated with thrips exposed to $P$. agglomerans, disease incidence was $70 \%$ at both 12 and 15 DPI (Fig. 2B).

Isolations were made from leaf tissues of seedlings displaying typical center rot symptoms, and identities of isolated colonies were confirmed. Yellow-colored (dark yellow areas within and 3 to $4 \mathrm{~mm}$ in diameter) and shiny colonies of $P$. ananatis were observed on the PA-20 semiselective medium. Colonies recovered on TSBA plates were yellow, gram-negative, utilized glucose as a facultative anaerobe, positive for indole, and negative for nitrate reductase. On further testing, DNA extracted from those colonies was amplified with primers specific for $P$. ananatis by real-time PCR.

Yellow-pigmented colonies of $P$. agglomerans were recovered from symptomatic onion seedlings on TSBA plates. The colonies were gram-negative, utilized glucose as a facultative anaerobe, negative for indole, and produced positive reaction for nitrate reductase. The nucleotide sequences of the $16 \mathrm{~S}$ rRNA gene from 10 isolates showed $100 \%$ similarity to $P$. agglomerans (PNG 06-1; accession no. KF805975). Negative controls in mechanical and thrips inoculation experiments did not produce any P. agglomerans infection. Surface-sterilized thrips used for thrips-mediated transmission also did not test positive for P. agglomerans. Absence of $P$. agglomerans in the negative controls and the similarity of the
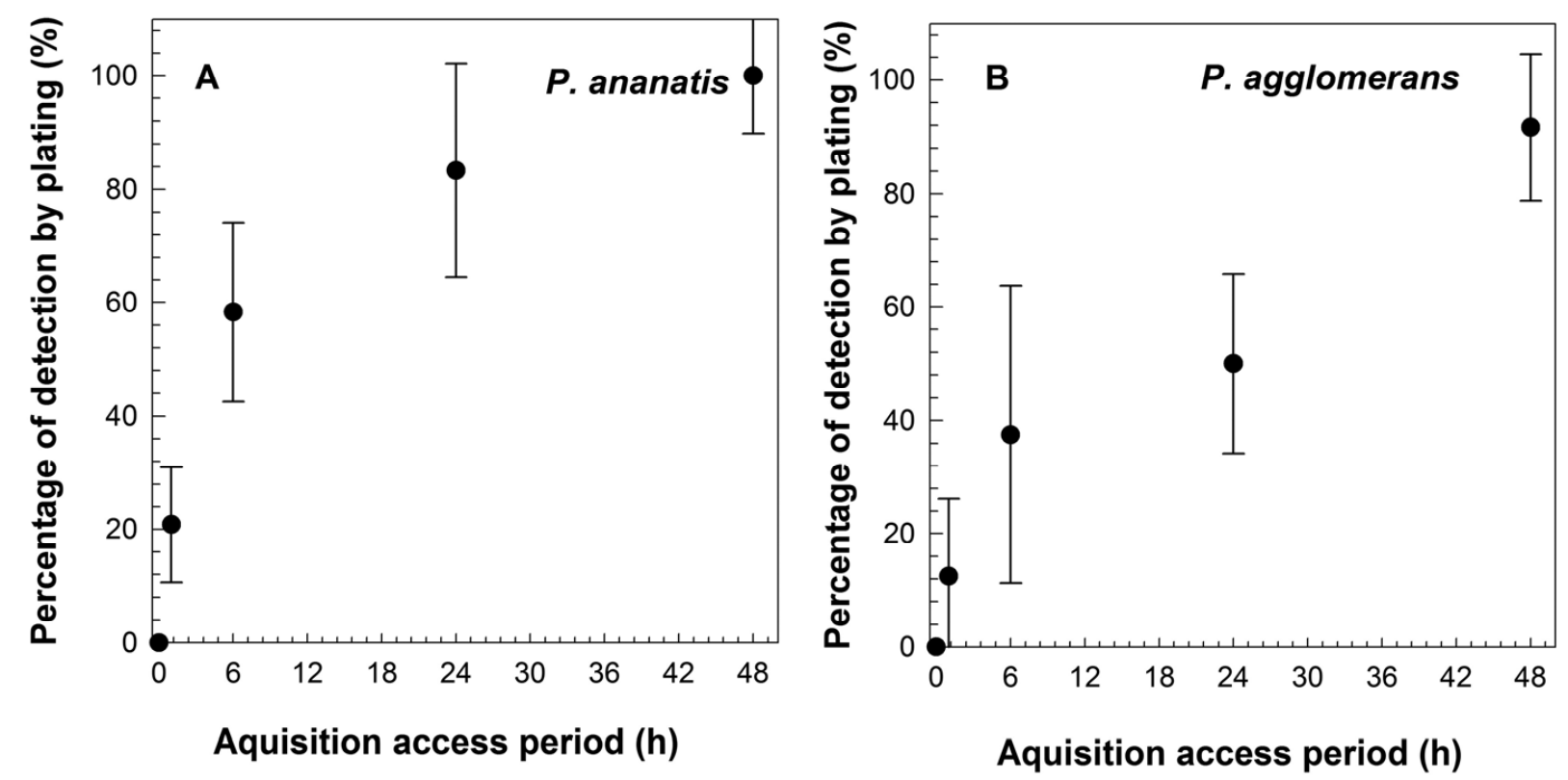

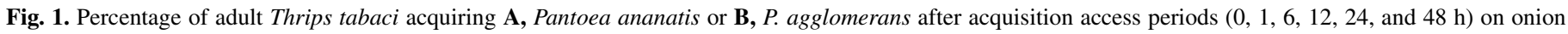

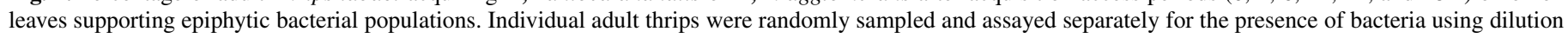
plating on respective semi-selective media. Four individuals were used at each acquisition access period, and the experiment was repeated five times. 
partial 16S rRNA sequences of isolated strain with the inoculated strain excluded contamination and confirmed infection by the inoculated bacterial strain.

Immunolocalization of $P$. ananatis in adult $\boldsymbol{T}$. tabaci. The anatomical features of $T$. tabaci were marked on the toluidineblue stained section as head, thorax, oesophagous (Oe), midgut 1 , 2, and $3(\mathrm{Mg} 1, \mathrm{Mg} 2$, and $\mathrm{Mg} 3)$, and hindgut $(\mathrm{Hg})$ (Fig. 3A and $\mathrm{C}$ ) (19). Sections of negative controls (T. tabaci on PBS-treated onion leaves) that were labeled with anti-rabbit IgG conjugated with Alexa-fluor 488 alone did not produce fluorescent signals, which indicated the absence of nonspecific binding of the secondary antibody to thrips tissues (figure not shown). Additionally, fluorescence was not observed in sections of negative control thrips, which were exposed to PBS-treated onion leaves. No fluorescence was observed in sections of thrips labeled with the anti-P. ananatis primary antibody (Fig. 3B). When the sections of T. tabaci were immunolabeled with primary and secondary antibodies and observed under a fluorescent microscope, immunolabeling of $P$. ananatis was visible in the $\mathrm{Oe}, \mathrm{Mg} 1, \mathrm{Mg} 2, \mathrm{Mg} 3$, and $\mathrm{Hg}$ (Fig. 3D). P. ananatis was not observed in any other tissues within thrips or on thrips surface.

Transmission of $\boldsymbol{P}$. ananatis to onion seedlings through T. tabaci saliva and feces. All of the seedlings that were mechanically inoculated with $P$. ananatis displayed typical center rot symptoms at 5 to $7 \mathrm{DPI}$. However, no symptoms were observed on seedlings when they were mechanically inoculated with sucrose solution potentially containing salivary sections. The sucrose solution, which provided nutrients for thrips, was trapped between parafilm membranes stretched on the top of microcentrifuge tube housing thrips. Also, bacterial colonies were not recovered from sucrose solution by spread-plating on PA-20 medium suggesting that $P$. ananatis was absent in salivary secretions and might not be transmitted via saliva. In two independent experiments, $65 \%$ of the onion seedlings that were inoculated with rinsates containing thrips feces developed center rot symptoms. $P$. ananatis colonies were recovered from $100 \%$ of the feces rinsates of thrips that were exposed to the bacterium for $72 \mathrm{~h}$. A subset of seedlings associated with each treatment that displayed putative center rot symptoms was confirmed to be infected with $P$. ananatis by pathogen isolation followed by real-time PCR assay. In addition, $P$. ananatis colonies were not recovered from sucrose solutions trapped between Parafilm membranes.

\section{DISCUSSION}

Our findings, for the first time, showed that $T$. tabaci could transmit $P$. ananatis and $P$. agglomerans, components of the onion center rot complex. Additionally, we found that $P$. ananatis was immunolocalized only in the gut of $T$. tabaci, which is characteristic of most members of the family Enterobacteriaceae. The absence of $P$. ananatis in other insect tissues such as salivary glands suggested that the bacterium is not circulative in the insect. Inoculation using feces rinsates indicated that $P$. ananatis could be transmitted via feces and through mechanical wounding. In addition, mechanical inoculation of sucrose solution containing salivary secretions did not result in center rot incidence in inoculated seedlings. This confirmed the noncirculative nature of $P$. ananatis in T. tabaci. Preliminary investigations revealed that there was no bacterial multiplication in the gut. Also, there was no evidence of specific interactions mediated by Pantoea sp. elsewhere in thrips. This suggested that transmission could merely represent transfer of Pantoea sp. from gut via feces following oral ingestion.

The observed transmission unlikely occurred due to surface contamination of the thrips with the pathogens and their further transfer to plant tissue because the thrips were surfaced-sterilized after the period of acquisition and last surface rinsates did not produce any colonies after plating onto semiselective agar. Further evidence for transmission through feces was provided by immunolabeling, which clearly revealed that the bacterium was only localized in the gut and nowhere else on the insect. Additionally, the fecal rinsates produced $P$. ananatis colonies following plating. Two separate experiments were conducted to assess acquisition and transmission of Pantoea sp. by $T$. tabaci. The former experiment revealed that $T$. tabaci could indeed acquire both $P$. ananatis and $P$. agglomerans following an AAP. In the latter experiment, thrips were allowed to acquire the pathogen and then used to inoculate onion seedlings. Disease incidence was observed in inoculated plants following inoculation. The incidence of infection was a consequence of acquisition, retention, latency, and inoculation indicating that $T$. tabaci indeed transmitted Pantoea sp.

A positive exponential relationship was observed between AAP duration and Pantoea sp. acquisition. Acquisition assays indicated that T. tabaci adults acquired both bacterial species within 1-h

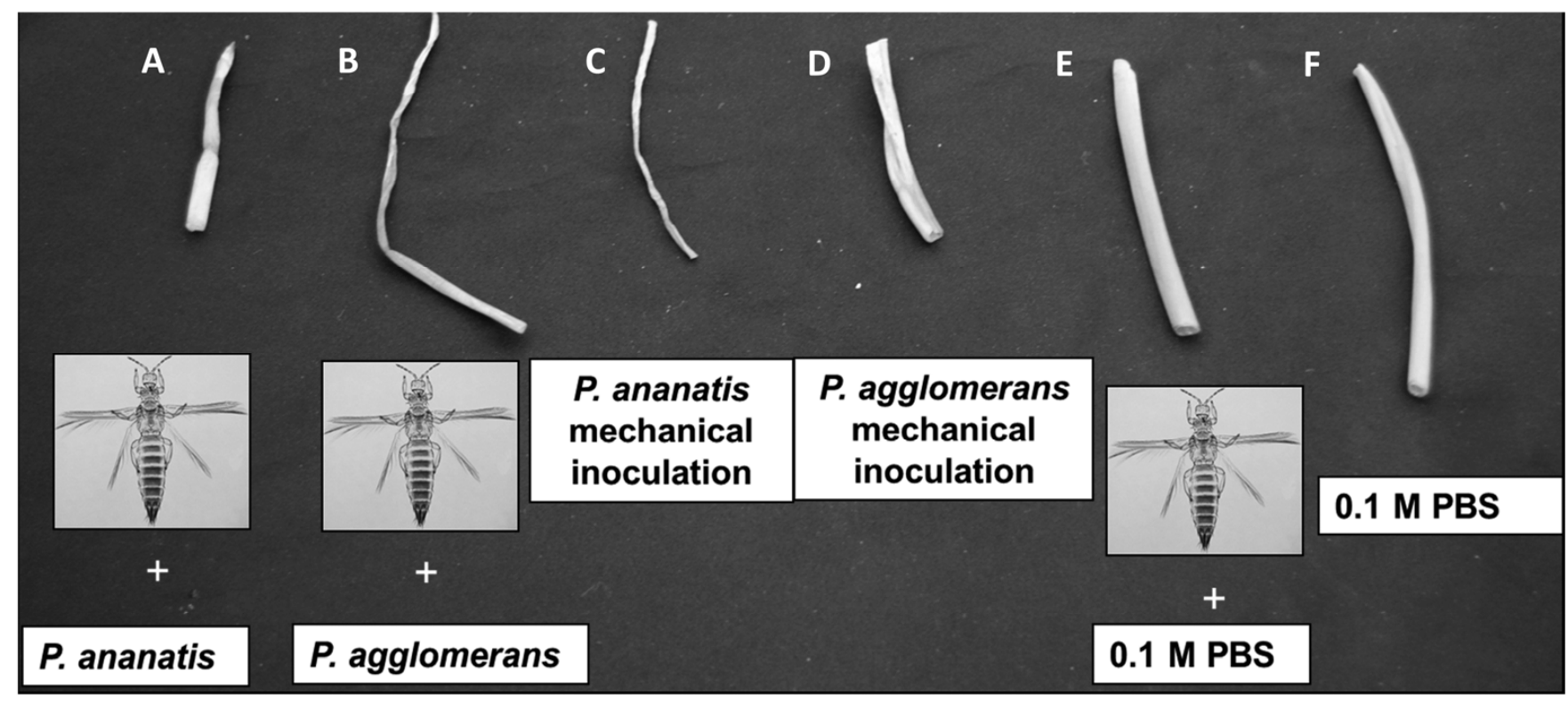

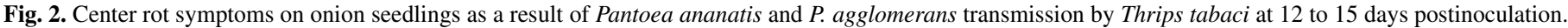

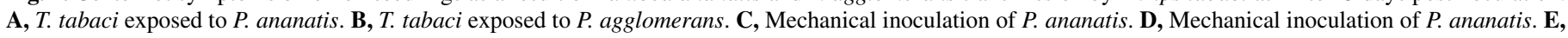
T. tabaci exposed to phosphate-buffered saline (PBS)-inoculated leaves. F, PBS control. 
AAP. At 48-h AAP, 100 and $92 \%$ of T. tabaci adults had acquired $P$. ananatis and $P$. agglomerans, respectively. Such high acquisition rates could also be attributed to high epiphytic bacterial populations used in this study where the leaves were inoculated with $1 \times 10^{6} \mathrm{CFU} / \mathrm{ml}$ suspension. Similar observations were made in the case of Xylella fastidiosa and glassy-winged sharpshooter (Homalodisca vitripennis Germar) pathosystem, in which bacterial acquisition efficiency was dependent on the pathogen population and the length of AAPs (5). The authors also observed that low pathogen populations and short feeding periods reduced the probability of acquiring $X$. fastidiosa from infected plants. In our study, acquisition efficiency of T. tabaci was not evaluated with low pathogen populations such as $10^{1}$ or $10^{3} \mathrm{CFU} / \mathrm{ml}$, but similar effects of pathogen population on acquisition of Pantoea by $T$. tabaci could occur.

Additionally, it was noticed that $T$. tabaci adults acquired $P$. ananatis at a slightly higher frequency than $P$. agglomerans; however, the observed difference was only numerical and no statistical comparisons were made. Bell et al. (2) also observed differential acquisition of $P$. ananatis and $P$. agglomerans by
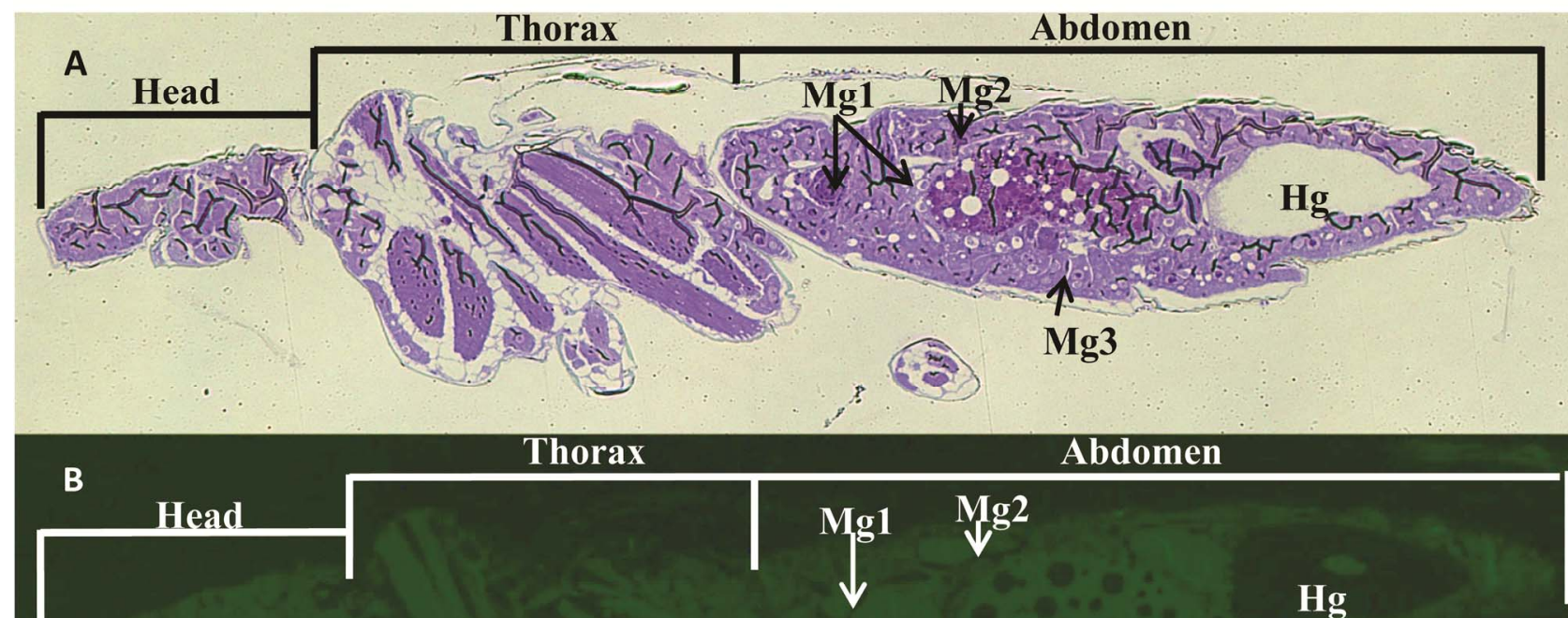

Abdomen
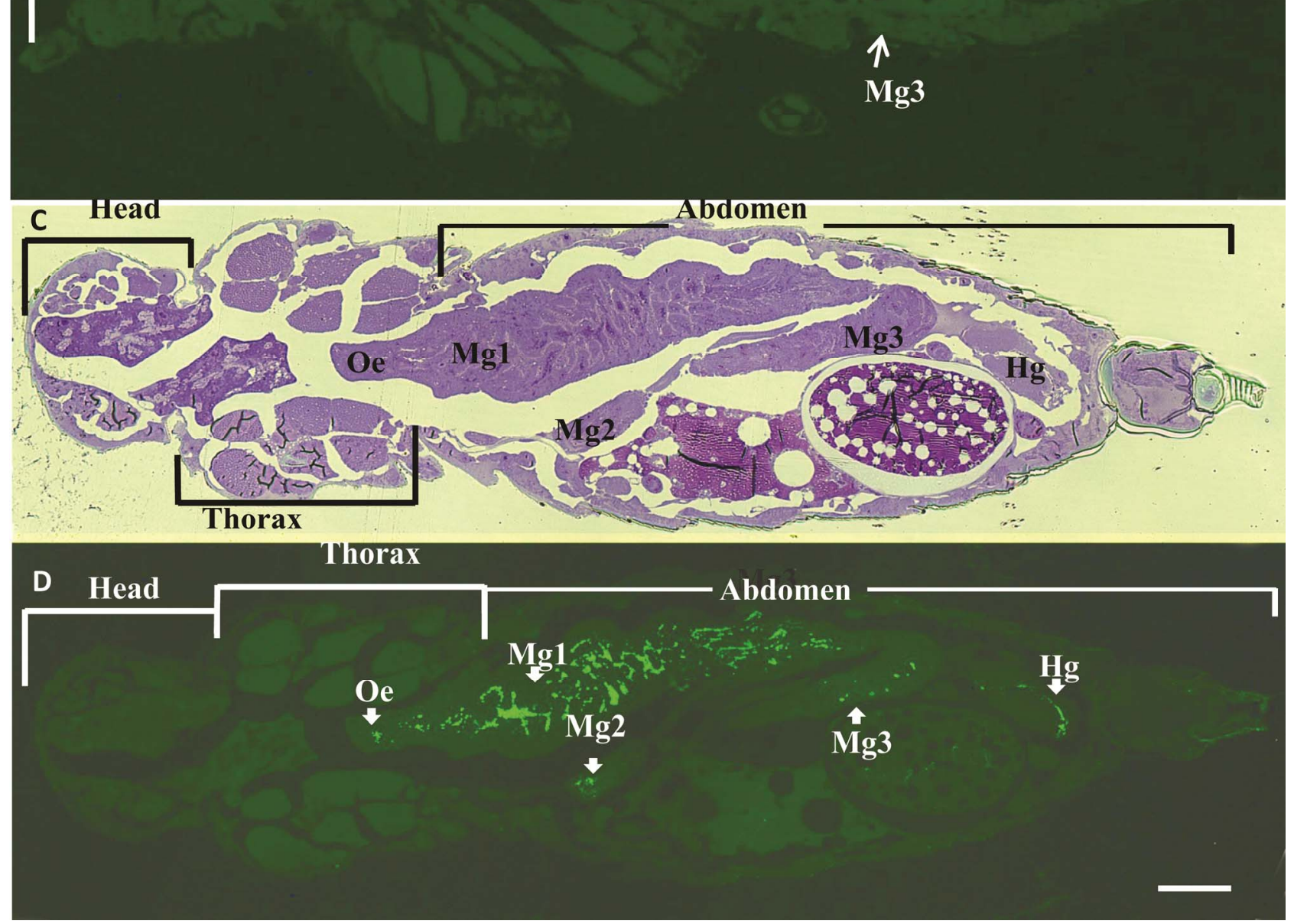

Fig. 3. Immunolocalization of Pantoea ananatis in adult Thrips tabaci. A, Micrograph of negative control T. tabaci stained with toluidine blue dye. B, Immunolabeled micrographs of negative control T. tabaci. C, T. tabaci micrograph stained with toluidine blue dye that fed on epiphytic populations of P. ananatis. D, Immunolabeled micrograph of $T$. tabaci fed on epiphytic populations of P. ananatis. Oe, oesophagus; Mg1, midgut 1; Mg2, Midgut 2; Mg3, midgut 3; and $\mathrm{Hg}$, hindgut. Fluorescing green areas show the localization of P. ananatis cells in the gut of T. tabaci. Bars in panels A to D correspond to $100 \mu \mathrm{m}$. 
cotton fleahoppers (Pseudatomoscelis seriatus Reuter). Experiments using rifampicin-resistant strains of $P$. ananatis and $P$. agglomerans revealed that fleahoppers only acquired $P$. ananatis even when $P$. agglomerans was present on bean leaves. The authors speculated the differential acquisition was due to the ability of $P$. ananatis to colonize fleahoppers guts, and/or the bacterium's ability to competitively exclude $P$. agglomerans. If there were any differential acquisition of Pantoea sp. by T. tabaci, it was not extreme, as both $P$. ananatis and $P$. agglomerans were acquired efficiently by $T$. tabaci. Similarly, both bacterial species were transmitted by T. tabaci to onion seedlings, whereas cotton fleahopper only transmitted $P$. ananatis (2).

T. tabaci with a 48-h AAP efficiently transmitted both $P$. ananatis and $P$. agglomerans $(\geq 70 \%)$. Preliminary investigations with thrips plating following AAP revealed that the percentage of $T$. tabaci infected with $P$. ananatis decreased over time. This suggested that bacteria might not be multiplying within thrips. However, the estimation of bacterial populations in subsamples of thrips indicated that individual thrips acquired $\geq 3 \times 10^{5} \mathrm{CFU}$ of $P$. ananatis and $2.1 \times 10^{5} \mathrm{CFU}$ of $P$. agglomerans in $48 \mathrm{~h}$. Such high levels of bacteria in individual thrips could have contributed to the observed high transmission percentages. Gitaitis et al. (12) reported that, when 6 to 12 individuals of $F$. fusca harboring populations of $P$. ananatis of $1 \times 10^{3} \mathrm{CFU} / \mathrm{ml}$ or greater were exposed to noninfected onion seedlings, $52 \%$ of the onion seedlings developed center rot symptoms. However, in that case, symptoms were observed within 6 to 9 days. Although, bacterial populations estimated per thrips were lower than observed in this study, disease symptoms were observed sooner. This difference could have been due to differences in bacterial population estimation in thrips. We used a direct bacterial enumeration by crushing individual thrips. In contrast, Gitaitis et al. (12) enumerated bacterial populations in thrips via an indirect assay. The adopted indirect method might have resulted in an underestimation of $P$. ananatis populations in $F$. fusca in their study. Additionally, variability within bacterial strains could affect the time required for symptom development. The disease progress curves for two bacterial species transmitted by T. tabaci displayed a similar trend. Center rot symptoms were not observed on plants that were exposed to T. tabaci that fed on PBS-inoculated leaves.

Based on historical observations of center rot epidemiology, including presence of a primary disease gradient and association of $P$. ananatis and $P$. agglomerans with field-collected $T$. tabaci (data not shown), it is possible that onion thrips could play a critical role in disease spread in the onion field. However, such gradients might be also attributed to mechanical transmission by equipment (11) or a source of inoculum such as weeds that is located adjacent to the field. Nonetheless, repeated applications of copper sprays have regularly failed to control the spread of center rot. Perhaps, the failure of these sprays could be due to thrips colonization at the basal meristems (neck region) and thereby allowing bacteria to evade bactericidal sprays or due to reinvasions of thrips harboring Pantoea sp.

$P$. ananatis and $P$. agglomerans are members of the family Enterobacteriaceae. In general, members of this family are considered primarily as gut residing in thrips and in other insects $(6,23)$. Our immunolocalization study using antibodies specific to $P$. ananatis showed that the bacterium was not present outside of the gut of T. tabaci. The bacterium was found in the lumen of the $\mathrm{Oe}, \mathrm{Mg} 1, \mathrm{Mg} 2, \mathrm{Mg} 3$, and $\mathrm{Hg}$. The absence of $P$. ananatis in other insect tissues besides the gut lumen and lack of transmission from collected salivary secretions led us to hypothesize that the transmission could occur via fecal contamination. Further, mechanical inoculation of rinsates containing $P$. ananatis-contaminated feces on noninfected onion seedlings led to center rot symptom expression in $100 \%$ of the inoculated plants. These results are in accordance with the observations previously made by Gitaitis et al. (12) that the bacterium could be transmitted through feces.
Thrips have asymmetrical mouthparts; they possess a single mandible that pierces plant cells creating a wound. In addition, they could defecate directly on or in proximity to the wounds induced by feeding. Under these conditions, there is a high probability that bacteria in feces can infect the host plant (15). Though there is no evidence of the movement of $P$. ananatis from the gut to salivary glands, it is possible that thrips could still acquire $P$. ananatis on their mouthparts due to surface contamination while feeding on infected sites and inoculate to other uninfected sites through their feeding behaviors such as noningestive probes and salivation $(15,26,27)$. Immunolocalization and mechanical inoculation (feces and salivary secretions) experiments were conducted only with $P$. ananatis. We hypothesize that $P$. agglomerans also would be transmitted in a similar fashion, as they are both Enterobacteriaceae members within the same genera.

Despite the evidence for transmission of gut bacteria such as Pantoea sp. through thrips feces, transmission of the same by mere surface contamination of mouthparts and/or other appendages cannot be completely ruled out. This potential aspect of the pathogen transmission is worthy of further investigation.

\section{LITERATURE CITED}

1. Azad, H. R., Holmes, G. J., and Cooksey, D. A. 2000. A new leaf blotch disease of sudangrass caused by Pantoea ananas and Pantoea stewartii. Plant Dis. 84:973-979.

2. Bell, A. A., Medrano, E. G., Lopez, J. D., and Luff, R. K. 2007. Transmission and importance of Pantoea ananatis during feeding on cotton buds (Gossypium hirsutum L.) by cotton fleahoppers (Pseudatomoscelis seriatus Reuter). Proceedings of the World Cotton Research Conference, Lubbock, Texas.

3. Bruton, B. D., Wells, J. M., and Lester, G. E. 1986. Pathogenicity of Erwinia ananas muskmelons in Texas. (Abstr.) Phytopathology 76:1136.

4. Coutinho, T. A., Preisig, O., Mergaert, J., Cnockaert, M. C., Riedel, K. H., Swings, J., and Wingfield, M. J. 2002. Bacterial blight and dieback of Eucalyptus species, hybrids, and clones in South Africa. Plant Dis. 86:2025.

5. Daugherty, M. P., and Almeida, R. P. P. 2009. Estimating Xylella fastidiosa transmission parameters: decoupling sharpshooter number and feeding period. Entomol. Exp. Appl.132:84-92.

6. de Vries, E. J., Breeuwer, J. A. J., Jacobs, G., and Mollema, C. 2001. The association of western flower thrips, Frankliniella occidentalis, with a near Erwinia species gut bacteria: transient or permanent? J. Invertebr. Pathol. 77:120-128.

7. Diffe, S., Edwards, G. B., and Mound, L. A. 2008. Thysanoptera of southeastern U.S.A.: A checklist for Florida and Georgia. Zootaxa 1787:45-62.

8. Edens, D. G., Gitaitis, R. D., Sanders, F. H., and Nischwitz, C. 2006. First report of Pantoea agglomerans causing a leaf blight and bulb rot of onions in Georgia. Plant Dis. 90:1551.

9. Gitaitis, R., Walcott, R., Culpepper, S., Sanders, H., Zolobowska, L., and Langston, D. 2002. Recovery of Pantoea ananatis, causal agent of center rot of onion, from weeds and crops in Georgia, USA. Crop Prot. 21:983989.

10. Gitaitis, R. D., and Gay, J. D. 1997. First report of a leaf blight, seed stalk rot, and bulb decay of onion by Pantoea ananas in Georgia. Plant Dis. 81:1096.

11. Gitaitis, R. D., Stall, R. E., and Strandberg, J. O. 1978. Dissemination and survival of Pseudomonas alboprecipitans ascertained by disease distribution. Phytopathology 68:227-231.

12. Gitaitis, R. D., Walcott, R. R., Wells, M. L., Diaz Perez, J. C., and Sanders, F. H. 2003. Transmission of Pantoea ananatis, causal agent of center rot of onion, by tobacco thrips, Frankliniella fusca. Plant Dis. 87:675-678.

13. Goszczynska, T., Venter, S. N., and Coutinho, T. A. 2006. PA-20, a semiselective medium for isolation and enumeration of Pantoea ananatis. J. Microbiol. Methods. 64:225-231.

14. Hattingh, M. J., and Walters, D. F. 1981. Stalk and leaf necrosis of onion caused by Erwinia herbicola. Plant Dis. 65:615-618.

15. Kumar, N. K. K., Ullman, D. E., and Cho, J. J. 1995. Resistance among Lycopersicon species to Frankliniella occidentalis (Thysanoptera: Thripidae). J. Econ. Entomol. 88:1057-1065.

16. Medrano, E. G., and Bell, A. A. 2007. Role of Pantoea agglomerans in opportunistic bacterial seed and boll rot of cotton (Gossypium hirsutum) grown in the field. J. Appl. Microbiol. 102:134-143.

17. Mitchell, R. F., and Hanks, L. M. 2009. Insect frass as a pathway for 
transmission of bacterial wilt of cucurbits. Environ. Entomol. 38:395-403.

18. Munger, F. 1942. A method of rearing citrus thrips in the laboratory. J. Econ. Entomol. 35:373-375.

19. Nagata, T., Nagata-Inoue, A. K., Smid, H. M., Goldbach, R., and Peters, D. 1999. Tissue tropism related to vector competence of Frankliniella occidentalis for tomato spotted wilt tospovirus. J. Gen. Virol. 80:507-515.

20. Nischwitz, C., Gitaitis, R., Sanders, H., Langston, D. B., Mullinix, B., Torrance, R., Boyhan, G., and Zolobowska, L. 2007. Use of fatty acid methyl ester profiles to compare copper-tolerant and copper sensitive strains of Pantoea ananatis. Phytopathology 97:1298-1304.

21. Schwartz, H. F., and Otto, K. 2000. First report of a leaf blight and bulb decay of onion by Pantoea ananatis in Colorado. Plant Dis. 84:808

22. Serrano, F. B. 1928. Bacterial fruitlet brown rot on pineapple in the Philippines. Philippine J. Sci. 36:271-305.

23. Sims, K. R. 2010. Interactions between Frankliniella fusca (Thysanoptera: Thripidae), Thripinema fuscum (Tylenchida: Allantonematidae), and entomoparasites (Tomato spotted wilt virus, Pantoea ananatis and Wolbachia sp.). Ph.D. Dissert. The University of Florida, Gainesville.

24. Sparks, A. N., Diffe, S., and Riley, D. G. 2011. Thrips species composition shift on onions in the Vidalia region of Georgia. J. Environ. Sci. 46:40-45.

25. Srinivasan, R., Diffie, S., Sundaraj, S., Mullis, S. W., Riley, D., Gitaitis, R., and Pappu, H. R. 2011. Evaluation of lisianthus as an indicator host for Iris yellow spot virus. Plant Dis. 95:1520-1527.
26. Stafford, C. A., Walker, G. P., and Ullman, D. E. 2011. Modification of vector feeding behavior is a conserved trait for plant and animal viruses. Proc. Natl. Acad. Sci. 108:9350-9355.

27. Stafford, C. A., Walker, G. P., and Ullman, D. E. 2012. Hitching a ride: Vector feeding and virus transmission. Commun. Integr. Biol. 5:43-49.

28. Stall, R. E., Alexander, L. J., and Hall, C. B. 1969. Effect of Tobacco mosaic virus and bacterial infections on occurrence of graywall of tomato. [Erwinia ananas]. Fla. State Hortic. Soc. Proc. 81:157-161.

29. Ulman, D. E., Sherwood, J. L., and German, T. L. 1997. Thrips as vectors of plant pathogens. Pages 539-565 in: Thrips as Crop Pests. T. Lewis, ed. CAB International, New York.

30. Walcott, R. R., Gitaitis, R. D., Castro, A. C., Sanders, F. H., Jr., and DiazPerez, J. C. 2002. Natural infestation of onion seed by Pantoea ananatis, causal agent of center rot. Plant Dis. 86:106-111.

31. Weisburg, W. G., Barns, S. M., Pelletier, D. A., and Jane, D. J. 1991. 16S ribosomal DNA amplification for phylogenetic study. J. Bacteriol. 173:697-703.

32. Wells, J. M., Sheng, W. S., Ceponis, M. J., and Chen, T. A. 1987. Isolation and characterization of strains of Erwinia ananas from honeydew melons. Phytopathology 77:511-514.

33. Wells, M. L., Gitaitis, R. D., and Sanders, F. H. 2002. The Association of tobacco thrips. Frankliniella fusca (Thysanoptera: Thripidae) with two species of bacteria of the genus Pantoea. Ann. Entomol. Soc. Am. 95:719723. 